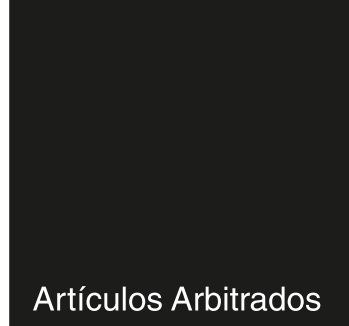

\title{
El urbanismo como nueva disciplina en Argentina, visto por el especialista Benito J. Carrasco, a través del plan regulador y de extensión para la ciudad de Córdoba, 1927
}

\section{José Ignacio Stang}

Arquitecto FAUD-UNC. Doctorando FAU-UNLP. Becario doctoral CONICET, CIECS-CONICET-UNC. Profesor asistente, cátedra Introducción a la Historia de la Arquitectura y el Urbanismo, FAUD-UNC. Investigador adscripto del Instituto de Conservación del Patrimonio Arquitectónico y Urbano, FAUD-UNC. Integrante del programa de investigación Sobre los lugares del Habitar y de la Memoria, CIECS-CONICET-UNC.

josestang@conicet.gov.ar.

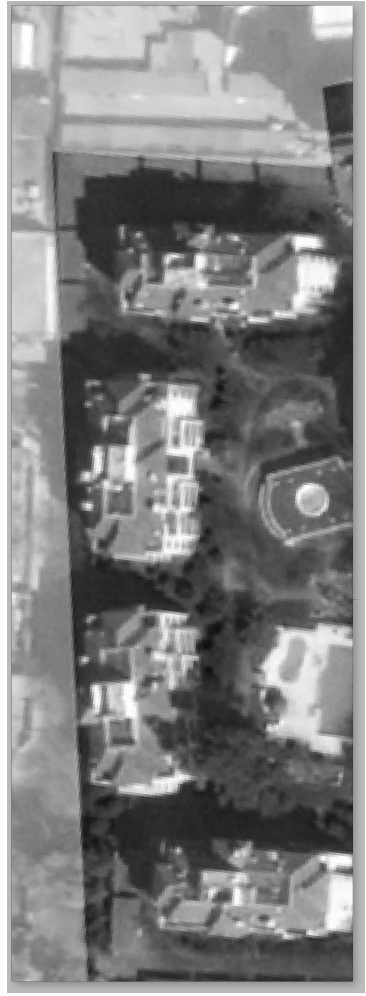




\section{Resumen}

El presente artículo indaga en el urbanismo como nueva disciplina emergente durante la década de 1920 en Argentina y en el plan desarrollado por los especialistas como nueva figura e instrumento regulador de la ciudad. Se analiza para ello la propuesta conceptual y de diseño que el ingeniero Benito J. Carrasco elabora en el plan de regulación y extensión para la ciudad de Córdoba. Se considera que los aportes de Carrasco en lo urbano forman parte de la historia de la urbanística argentina y significan un modelo alternativo de la realidad urbana en ese entonces. Su propuesta para Córdoba pone el acento en la copia o adaptación acrítica de soluciones elaboradas en otras latitudes, concebidas como modelos que, si bien no generaron el suficiente consenso para su materialización, introdujeron temas que resultaron recurrentes dentro del urbanismo cordobés a lo largo del siglo XX.

\section{Palabras clave}

Urbanismo; especialistas; plan regulador.

\section{Abstract}

Urban planning as a new discipline in Argentina as evidenced from Benito J. Carrasco's regulatory and extension plan for the city of Córdoba, 1927

This article explores urban planning as a new emerging discipline in Argentina during the 1920s using plans developed by specialists as the new regulatory instrument for cities. To that end, the concepts and design proposal of Engineer Benito J. Carrasco for the regulation and extension plan for the city of Córdoba are analyzed. Carrasco's contributions in the urban field are part of the history of Argentine urban planning and meant an alternative model to the urban reality of that moment. His proposal for Córdoba focused on the uncritical copy or adaptation of solutions developed in other latitudes and conceived as models which did not generate consensus for their realization, but they introduced recurrent topics wi thin Cordoba's urban planning throughout the 20th century.

\section{Keywords}

Urbanism, specialists, regulatory plan. 
El urbanismo como nueva disciplina en Argentina, visto por el especialista Benito J. Carrasco, a través del plan regulador y de extensión para la ciudad de Córdoba, 1927

\section{Introducción}

En la década de 1920, se produce en Argentina un cambio en el discurso acerca de la ciudad, sus problemas y las propuestas para su transformación, como así también sobre un nuevo saber que se encontraba en los primeros años de su constitución como disciplina en el país: el urbanismo. Durante esta década será el momento en que se inicie un reconocimiento sobre la especificidad disciplinar y cuando se comiencen a formar los primeros especialistas locales, ya que hasta entonces, cuando no se recurría a expertos extranjeros, "los profesionales locales que intervenían procedían, en general, de disciplinas afines (ingenieros civiles, agrónomos, agrimensores o arquitectos) y desde éstas se preocupaban por la escala urbana" (Collado, 2007: 379).

Los temas referidos a la extensión de la planta urbana y las cuestiones de embellecimiento, que solo en parte se relacionan con aquellos tratados con esos mismos términos a fines del siglo XIX, dejan de ser exclusividad de los circuitos intelectuales y de especialistas para hacerse públicos. ${ }^{1} \mathrm{El}$ problema asume una centralidad inédita como objeto de reflexión disciplinar y profesional. La disciplina del urbanismo, como un inventario de instrumentos empírico-científicos, una síntesis operativa de la evolución y transformación de la ciudad en que actúan operadores y especialistas (Sica, 1978: 34), surge junto a la figura del especialista como actor posible de dar soluciones a las urgencias urbanas.

Desde la emergente disciplina, la concepción totalizante que se buscaba ejecutar en los planes propuestos no podía ser percibida por todos. Para apreciarla era necesario contar con una educación profesional o, por lo menos, con experiencia práctica y, por lo tanto, también "estar preparado para considerar simultáneamente los múltiples problemas que deben ser conciliados en el plan de la ciudad. Un tipo específico de profesional debía estar a cargo de esta tarea, el que debía ser un especialista" (OutTes, 2002: 26). Entre la nómina de especialistas en Argentina para ese entonces, se destacan distintos y diversos profesionales que desarrollan sus actividades
1. En Latinoamérica, a partir de 1920 los problemas urbanos pasaron a ser cuestiones públicas (ALMANDOZ, 2013, 2007). Un ejemplo claro de ello fue la realización en septiembre de 1920 del primer Congreso Argentino de la Habitación, en el cual se discutieron en forma conjunta las problemáticas urbanas detectadas a partir de la intervención y la participación de distintos sectores. Junto a ello, las nuevas condiciones políticas, establecidas por las nuevas reglas en los procesos electorales que otorgaban un mayor protagonismo a los sectores populares (Ley Sáenz Peña en 1912) también fueron generando un clima de apertura hacia temas sociales desde el Estado. La vivienda, que había sido el eje del mencionado congreso, se incorpora como cuestión inherente al crecimiento y bienestar de la ciudad sumándose para ello diversos actores. Así, a los conceptos de estética, salubridady circulación que rigieron las propuestas anteriores de ingenieros, agrimensores $e$ higienistas, se añadieron las ideas de reforma social referentes a las condiciones de vida urbanas y a la vivienda económica. La escala de intervención superó la de algunos conjuntos edilicios o ejes viales para alcanzar la totalidad de la planta urbana y sus posibles extensiones en el tiempo y el espacio, incluso, a escala regional (RIGotTI, 2009). 
2. Si bien en las décadas anteriores diversos planes fueron elaborados para distintas ciudades (Plan de Extensión y Puerto para Rosario de 1891, Plan de Reforma y Extensión para Bahía Blanca de 1906, Plan de Reforma y Extensión para Buenos Aires de 1909, Plan de Reforma y

Extensión para Rosario de 1911, Proyecto de Ampliación para Mendoza de 1917), recién a partir de 1920 se consagra el nombre y asignación de plan regulador, denominación que aún perdura, aunque hoy expresa concepciones diferentes.

3. En dicha nómina, se encuentran el plan de Buenos Aires (Proyecto Orgánico-1925), Santa Fe (1927), Córdoba (1927) y Concordia (1929) (BRAGOS, 1997). principalmente en el ámbito de Buenos Aires. Los especialistas aparecen así con un discurso que se refiere a una técnica, una ciencia, un saber específico, y emerge además junto con ello la denominación, asignación y puesta en marcha de los planes reguladores. ${ }^{2}$

A partir de 1920, el desarrollo industrial, la movilidad demográfica y la expansión urbana habían evidenciado, en muchas urbes latinoamericanas, la urgencia de adoptar (y adaptar) planes que fueron emprendidos principalmente por los gobiernos locales apoyados en principio en expertos foráneos y luego por las nuevas generaciones de profesionales (Almandoz, 2013, 2007). Se confirma, así, la especialización de la disciplina junto con un discurso que acompañará a la emergencia del urbanismo. En dicho devenir, el plan regulador, como instrumento de gestión, cobra en Argentina una pronta adhesión entre las administraciones municipales y provinciales. La mayoría de los planes propuestos fueron el resultado de la contratación directa de los incipientes expertos especialistas por parte de las administraciones. Entre la nómina de los primeros planes que se realizaron ${ }^{3}$, el propuesto por Benito J. Carrasco para la ciudad de Córdoba en 1927 fue pionero como instrumento propositivo de composición y una cierta regulación. Así, la figura de Carrasco, ingeniero y paisajista, cobra relevancia en cuanto comienza a ser consultado como uno de los especialistas locales en materia de urbanismo, y por ser quien realizará los primeros planes para ciudades argentinas donde se pondrán de manifiesto y en práctica las recomendaciones concluidas del Primer Congreso Argentino de la Habitación (Bragos, 1998).

Desde el urbanismo como nueva disciplina emergente y desde el plan como figura e instrumento regulador de la ciudad, el artículo focaliza la mirada en el plan regulador y de extensión para Córdoba elaborado por Carrasco en 1927. Interesa la mirada sobre el plan como instrumento que articula y condensa un estado del conocimiento sobre la cuestión urbana en un momento dado (Novick, 2009), en el cual surgen los siguientes interrogantes: ¿cuál es el discurso que valida la emergencia de los planes reguladores en Argentina y en Córdoba en particular?; ¿cuáles son sus contenidos?; ¿qué y cómo se pretende resolver?; ¿qué consecuencias surgieron luego sobre la ciudad construida?

A partir de estas primeras preguntas, se propone como hipótesis inicial que el plan de Carrasco para Córdoba elabora la importación acrítica de un discurso sobre la ciudad y sus problemas y sobre el urbanismo como un nuevo saber que, al estar en sus primeros años 
El urbanismo como nueva disciplina en Argentina, visto por el especialista Benito J. Carrasco, a través del plan regulador y de extensión para la ciudad de Córdoba, 1927

de constitución como disciplina en el país, todavía se encontraba atravesado por el arte urbano como concepción clásica acerca de la intervención en la ciudad. Si bien la propuesta del plan regulador de Carrasco para la ciudad de Córdoba no generó el suficiente consenso para su materialización, a partir de la copia o adaptación acrítica de soluciones elaboradas en otras latitudes y asumidas como modelos, introdujo ciertos temas que resultaron recurrentes dentro del urbanismo cordobés durante el siglo XX.

Estructuralmente, el desarrollo del trabajo comienza con una breve reflexión respecto de la importancia que tuvo el Primer Congreso Argentino de la Habitación (realizado en septiembre de 1920). Se inicia la investigación a partir de este evento debido a que se considera que su relevancia como congreso fue más allá de abordar la problemática de la vivienda propiamente dicha. Se planteó la necesidad respecto de la previsión en materia de trazados urbanos, espacios verdes, zoning, tránsito y circulación, y se formularon y propusieron, además, sugerencias en cuanto a las modalidades posibles de regulación e intervención por parte del Estado. Este tipo de planteos son los que posibilitaron en este momento la adopción de un nuevo punto de vista sobre la ciudad y dieron lugar al posicionamiento tanto de los nuevos especialistas como de la ejecución de los planes reguladores. A partir de estos lineamientos, el trabajo propone seguidamente una lectura sobre el rol y lugar de los especialistas locales, particularmente sobre la figura de Carrasco entre ellos.

En segunda instancia, a partir de la lectura del plan regulador y de extensión para Córdoba, se busca exhibir la lógica de abordaje que asume Carrasco en la manera de hacer ciudad durante esa década. Entendiendo al urbanismo como acciones conscientes cuyo objetivo fue concebir, organizar, planificar o transformar la ciudad y su espacio en confluencia con la aparición a principios del siglo XX de una nueva disciplina en la que se unieron múltiples especialidades y experiencias prácticas (Novick y Piccioni, 2004), se propone leer a la emergente disciplina a partir del análisis del plan, como un nuevo dominio especializado del saber y de la acción (Rigotтi, 2009), que prometía encauzar el desarrollo y la integración social y económica de las ciudades y el territorio desde una perspectiva tecnocrática. En Argentina, la aspiración de superar saberes y prácticas dispersas signó el primer instrumento del urbanismo: el plan regulador (RigotTi, 2009).

Metodológicamente, el desarrollo de la investigación es de carácter cualitativo. Se considera que, para poder hacer una lectura del proyecto como del proyectista, es necesario el 
4. La identificación y asignación de distintas generaciones de planes se toma a partir de la enunciación de tres generaciones durante la primera mitad del siglo $X X$ propuesta por BRAGos (1997)

y que, cronológicamente, corresponden a los elaborados durante las décadas de los años veinte, treinta y cuarenta, respectivamente. Tres generaciones que dan cuenta de distintas perspectivas para aproximarse al conocimiento e interpretación de la ciudad, y de diferentes modos de entender su

transformación. El autor mencionado propone la constitución de la primera generación de planes reguladores en el urbanismo argentino tomando los planes de Buenos Aires (Proyecto Orgánico-1925), Santa Fe

(1927), Córdoba (1927)

y Concordia (1929), que caracteriza por atender privilegiadamente

la cuestión del

trazado e incorporar embrionariamente la idea de zoning. abordaje de una revisión del pensamiento y las ideas de la época referidas a la disciplina. Se recurrió para ello a la consulta de la memoria, documentación gráfica y escrita del plan y a escritos del autor, publicaciones en diarios de la época, artículos de opinión y conclusiones de congresos.

Se propone poner el foco en ciertas operaciones técnicas, acontecimientos y en un personaje en particular para indagar los argumentos desplegados en un determinado momento sobre el urbanismo en los primeros años de su constitución como disciplina en Argentina. La bibliografía consultada permite dar cuenta de que, sobre las denominadas generaciones de planes reguladores en Argentina ${ }^{4}$,existen ciertos estudios que abordan principalmente la mirada sobre los planes para las ciudades de Buenos Aires en 1925 (Novick, 2000; Molina y Vedia, 1999; SuÁrez, 1994; Bragos 1991), para Santa Fe en 1927 (Collado, 2007), Concordia en 1929 (CAnAvessi, 2012) y para Rosario en 1935 (Galimberti, 2016; Brarda, 2012; Rigotti, 1997; Novick y Piccioni, 1990; Martínez de San Vicente, 1986), siendo escasas, breves y tangenciales las referencias sobre lo que propone Carrasco para Córdoba en 1927 (DíAz Terreno, 2012 y 2005; Martínez y Rettaroli 1994; Page, 1991).

En relación con la indagación sobre la figura específica del especialista como actor protagonista en los inicios de la disciplina del urbanismo, se pueden destacar los trabajos de Adagio (1999) — quien los realiza desde la posición del arquitecto como artista urbano (capaz de interpretar la construcción material y simbólica de la ciudad) - y el de Novick y PIccionI (1990) — quienes lo abordan a partir del análisis específico de la figura de Carlos María Della Paolera en Buenos Aires-. En cuanto al debate sobre la traducción de modelos, enriquecen el intercambio la mirada propuesta por Rigotті (2003) — desde una indagación a partir de los préstamos y traducciones teórico-metodológicos que constituyen al urbanismo como disciplina en Argentina, y de la disputa por el campo urbano con otras profesiones y saberes-y la de Novick (2009) — que se basa en el análisis de los planes urbanísticos y de los proyectos que de ellos resultan-.

A partir de los antecedentes indagados, el presente artículo explora el urbanismo como nueva disciplina emergente durante la década de 1920 en Argentina, y el plan como nueva figura e instrumento regulador de la ciudad desarrollado por los especialistas. A través del análisis específico de la propuesta conceptual y de diseño que el Ing. Benito J. Carrasco elabora en el plan de regulación y extensión para la ciudad de Córdoba — proyecto que 
El urbanismo como nueva disciplina en Argentina, visto por el especialista Benito J. Carrasco, a través del plan regulador y de extensión para la ciudad de Córdoba, 1927

aún continúa poco explorado y estudiado-, se busca aportar elementos que enriquezcan el debate respecto del entendimiento de la actuación urbanística durante los inicios del urbanismo como disciplina en Argentina. ${ }^{5}$

\section{Sobre la trascendencia del Primer Congreso Argentino de la Habitación}

En septiembre de 1920, organizado por el Museo Social Argentino, se realizó en la ciudad de Buenos Aires el Primer Congreso Argentino de la Habitación. Fue de gran importancia para el urbanismo argentino, dado que allí se discutió por primera vez en forma conjunta la problemática de la vivienda, en particular la vivienda social, y junto a ello el plan de ordenamiento urbano. Estas dos cuestiones hasta el momento habían sido tratadas en forma separada en el país y, en lo referido al plan urbano, de manera insuficiente y ocasionalmente.

El congreso tiene como antecedente directo la crisis habitacional que se venía gestando. La precariedad y escasez de viviendas y la incesante alza en el precio de alquileres indujeron al gobierno a sancionar distintas leyes con la finalidad de fijar los valores de la renta. En 1920, durante el gobierno del presidente Hipólito Yrigoyen, el Congreso de la Nación sancionó la Ley de Emergencia Habitacional 11.157, en virtud de la cual se congelaban por el plazo de dos años los precios de los alquileres fijándolos al 21 de enero de 1920. También se apuntaba a la prórroga y suspensión de los juicios por desalojo y a la obligación por parte de los propietarios de denunciar las casas y departamentos desocupados.

El problema de la vivienda no fue una cuestión arbitraria. El crecimiento de las ciudades era cada vez mayor, debido a las oleadas de pobladores que en número creciente se radicaban en el radio urbano. La inmigración era fundamentalmente de trabajadores extranjeros sin recursos que se incorporaban al mercado de trabajo local a través de las más variadas formas de inserción. El ritmo de crecimiento condujo a preguntarse acerca del problema de su alojamiento y a colocar a la vivienda como problema para solucionar, además de acentuar de manera creciente la tensión y disputa entre grandes propietarios e inmobiliarias. "Es en este contexto, en el que la carestía de la vida y la legislación sobre congelamiento de alquileres enrarecen el clima social, cuando el Museo Social Argentino organiza el Primer Congreso Argentino de la Habitación” (Novick, 1993: 16).
5. El presente artículo es parte de una tesis doctoral, recientemente finalizada, que aborda el estudio de prácticas efimeras creativas en los espacios urbanos públicos del centro histórico de la ciudad de Córdoba en la actualidad. Si bien la investigación desarrollada no atraviesa completamente la perspectiva histórica, fue necesario recurrir a ella para la búsqueda de comprensión en la construcción del espacio centro histórico en la ciudad de Córdoba a partir del estudio de las estrategias desarrolladas. La conformación actual de los espacios urbanos tantos centrales, pericentrales como periféricos es consecuencia de diversas lógicas de actuación sobre el territorio a lo largo de la historia de la ciudad, las que para su comprensión exigen el conocimiento de las teorías, los haceres y los procesos específicos involucrados en su construcción. 
6. Los criterios recomendados fueron indicaciones respecto de los planes, la organización de la ciudad, los trazados, los barrios y la construcción de la ciudad.
El congreso se desarrolló a partir de distintas comisiones de trabajo que se encargaron de encarar y abordar las cuestiones relacionadas con la vivienda social y con el plan de ordenamiento urbano. En las conclusiones de la comisión de trabajo Sección de Municipalismo y Estadística, se establece una serie de criterios y recomendaciones referidos a la reglamentación de la extensión de las ciudades y a la implementación del plan. Disponen la necesidad de un especialista encargado de proyectar el plan, delimitan el papel del municipio en su elaboración y elaboran criterios que observar para desarrollarlo junto a medidas legales que se debían tomar para su ejecución. La presencia en ese momento de un especialista, capaz de asumir la responsabilidad y dar soluciones a los problemas urbanos, era la principal demanda.

La estrategia conformadora del urbanismo consistía en identificar problemas, proponer soluciones y consecuentemente convocar a un especialista que cargara con un saber específico. Para ese entonces, las ciudades conllevaban un acelerado crecimiento demográfico, los problemas eran otros y, por lo tanto, distintas debían ser las respuestas. Resultaba ya una situación inaceptable que la construcción de la ciudad se guiara con los mismos procedimientos desarrollados hasta ese momento. El resultado del diagnóstico fue destacar en reiteradas oportunidades la carencia de especialistas como problema, elaborar una serie de recomendaciones, a las cuales hoy se les asigna un gran valor, no por su incidencia concreta en el proceso de construcción de la ciudad, sino por su contribución a la conformación de un estatuto disciplinar del urbanismo. Formularon criterios que orientarán por un largo período el modo de elaborar un plan de ordenamiento urbano en el país. ${ }^{6}$

Como conclusión del congreso, cada sección elaboró sus diferentes recomendaciones. Desde la Sección de Acción Social se apuntó a medidas legales necesarias para que las propuestas de un plan regulador pudieran llegar a concretarse en la realidad, mediante el derecho de propiedad y fundamentalmente a partir de recomendaciones en relación con la redistribución de los beneficios de la renta a favor de la autoridad local. Desde la Sección de Legislación se fijaron pautas para la actuación de la autoridad local en relación con la vivienda social. Se planteó la erradicación progresiva de los conventillos, la exigencia a la autoridad municipal para asumir un papel protagónico en la construcción de viviendas económicas y sanas para los obreros y la provisión de servicios y equipamientos mínimos en los nuevos barrios para los trabajadores. Desde la Sección de Legislación, Municipalismo y Estadística, se planteó intensamente la necesidad de proveer a las ciudades en materia de trazados 
El urbanismo como nueva disciplina en Argentina, visto por el especialista Benito J. Carrasco, a través del plan regulador y de extensión para la ciudad de Córdoba, 1927

urbanos, espacios verdes, distribución funcional, tránsito y circulación, y formular sugestiones en cuanto a las modalidades posibles de regulación e intervención por parte del Estado.

El congreso estableció las primeras condiciones que definen los contenidos y el carácter de los planes urbanos en el país: la zonificación de la ciudad según actividades y grupos sociales (refiriéndose a distribución funcional y no a zoning como instrumento específico), y el embellecimiento mediante la diversidad de trazados en la actuación urbanística. Se puede decir entonces que las conclusiones del congreso fueron más allá de la problemática de la vivienda propiamente dicha. Este tipo de planteos implicó adoptar un nuevo punto de vista sobre los problemas de la ciudad, evitando acotarlos solamente al tema de la vivienda higiénica y salubre para el obrero, según las localizaciones y las soluciones anti-urbanas que estaban implícitas en muchas de las operaciones de vivienda de interés social realizadas hasta el momento. La ciudad y su extensión se hacían ahora presentes en toda su complejidad.

\section{La figura de los especialistas locales. Carrasco, entre parques y jardines}

La manera de hacer ciudad en Argentina durante este momento se comparaba regularmente con las formas, gestiones y soluciones desarrolladas en otras latitudes, principalmente europeas. Las obras y emprendimientos realizados en Buenos Aires a finales del siglo XIX y principios del XX, por ejemplo, son vistas en relación con las obras realizadas en París durante la administración de Haussman. La mayoría de los proyectos urbanos eran más cercanos al linaje del urbanismo académico, representado por la École des Beaux-Arts y, más tarde, por el Instituto de Urbanismo de la Universidad de París. La revista de este último, La vie urbaine, publicada desde 1919, llegaría a tener gran impacto entre las nuevas generaciones de profesionales latinoamericanos (GuTIÉRREZ, 2007, 1995).

A diferencia de los países europeos, donde la consolidación disciplinar estuvo asociada a la promulgación legislativa tanto a nivel nacional como municipal, el urbanismo latinoamericano será proclamado por nuevos planes para las capitales y grandes ciudades, los cuales ejercerán como partidas de nacimiento de la nueva disciplina (Almandoz, 2002). Si bien ya en la década de 1920 existían profesionales considerados como especialistas, HaRdoy (1926) destaca que, para ese entonces, tanto los especialistas como las instituciones interesadas y preocupadas por temas urbanos en el país eran escasos y, por ello, señala 
7. Benito Javier Carrasco: ingeniero agrónomo, discípulo y sucesor de Charles Thays, cofundador de Los Amigos de la Ciudad, pasó sin solución de continuidad del diseño de jardines a las inquietudes urbanísticas, siguiendo el camino trazado por la Landscape Architecture en Estados Unidos. Su biografía ha sido construida por Sonia Berjman en El pensamiento de Benito Carrasco: hacia una teoría paisajística argentina, Documentos de Arquitectura Nacional Americana $N .^{o} 30$.

8. Si bien este artículo indaga específicamente sobre el plan que Carrasco elabora para la ciudad de Córdoba, se destaca también en su actividad profesional, respecto de planes elaborados para otras ciudades, el proyecto de ampliación y rectificación del trazado para Mendoza (convocado por el gobierno municipal de Mendoza en 1915, propuesta que nunca se concretó), un modelo para una Ciudad Ideal (1923,

donde diseña una ciudad utópica a partir de los ideales que consideraba convenientes para ese entonces) y el Plan Regulador para Concordia (convocado por la Municipalidad de Concordia en 1929. Nunca se concretó lo proyectado). como los únicos especialistas interesados en temas urbanos a Della Paolera y Carrasco. ${ }^{7}$ Ambos especialistas eran de la ciudad de Buenos Aires y expresaban sus ideas y opiniones fundamentalmente a través de artículos que publicaban en la prensa escrita de esa ciudad. Carrasco, en el diario La Nación y Della Paolera en el diario La Razón.

Della Paolera, ingeniero civil y además con formación en el Institute d'Urbanisme de Paris, será para ese entonces el único urbanista diplomado en el país. En la década del veinte se comienza a destacar por sus contribuciones a la constitución de un cuerpo teórico en relación con la disciplina. Sin embargo, no realizará actividad profesional en el urbanismo hasta la década siguiente en que participó con una destacada actividad en Buenos Aires desde el año 1932 como encargado de la Dirección del Plan Regulador y de Urbanización y Extensión de la Ciudad de Buenos Aires y luego en la elaboración del Plan Regulador de Rosario en 1935. Encantado por las transformaciones que observa en ciudades europeas, y fundamentalmente por su formación académica, pretendía colocar al urbanismo en el país como una nueva disciplina de carácter científico. Difundirá consideraciones teóricas, herramientas metodológicas y experiencias. Como discípulo de Marcel Poëte, será quien planteará por primera vez en Argentina la necesidad de proceder al estudio de la evolución y desarrollo de la ciudad como una de las instancias metodológicas clave del proceso de elaboración de un plan regulador. Afirmaba que para llegar a comprender las manifestaciones actuales que hacen a la existencia de una ciudad, es necesario estudiarla desde su origen y seguir su evolución para poder establecer la continuidad de sus transformaciones vitales (Della Paolera, 1926). No solo desarrolló aspectos teóricos, sino que también presentó propuestas específicas para soluciones concretas.

Durante la década de 1920, será el ingeniero Carrasco quien desarrolle una actividad profesional en temas relacionados con el urbanismo ${ }^{8}$, remarcando que Della Paolera es el primero que plantea cuestiones referidas a la elaboración de un plan de ordenación urbana (adopción del zoning como instrumento, la elaboración de un plan regional, el estudio de la evolución urbana) que no se ven en estos planes reguladores de la denominada primera generación. Desde un inicio y consecuentemente con las conclusiones del Congreso de la Habitación, Carrasco 
El urbanismo como nueva disciplina en Argentina, visto por el especialista Benito J. Carrasco, a través del plan regulador y de extensión para la ciudad de Córdoba, 1927

mantuvo su preocupación en el tema de la vivienda social planteando la necesidad de resolverla desde la figura del plan. ${ }^{9}$ Si bien no consiguió incorporarla como un elemento importante del plan más allá de las propuestas estéticas y compositivas, es de destacar que fue quien dio el puntapié inicial en la elaboración de planes reguladores en el país buscando incorporar los criterios dictados en el congreso. El urbanismo será para Carrasco una ciencia positiva cuya virtud debe ocupar el primer puesto en la evolución de la cultura pública.

En ambos especialistas, tanto Carrasco como Della Paolera, hay encuentro en muchas de sus opiniones. La diferencia puede establecerse en que Della Paolera, por su formación, lo hizo principalmente desde una perspectiva científica, mientras que Carrasco lo fundamentó principalmente desde lo empírico. Carrasco justificó todas sus propuestas a partir de casos que consideraba los más conocidos y difundidos desde la experiencia internacional, y que en ese momento resultaban paradigmáticos. Della Paolera, por otra parte, además de utilizar la herramienta empírica a partir de los ejemplos de ciudades norteamericanas y europeas, produce argumentación teórica en relación con su formación.

Las ideas de Carrasco van a estar más orientadas al arte que a la ciencia. Sus propuestas parten de la premisa de embellecer las ciudades, de crear nuevos medios urbanos basados en los principios de la estética, de la beautificación de la ciudad. Sostenía que el urbanismo como ciencia, a la que consideraba compleja, debía resolver problemas de trazados de acuerdo con las características del suelo y las demandas funcionales. Así, la finalidad del urbanismo como disciplina se va a ver reducida desde la óptica del especialista Carrasco al embellecimiento o beautificación de la ciudad. Utiliza la metáfora organicista cuando necesita describir el ideal de ciudad que imaginaba. Le vale en cuanto es utilizada como herramienta para garantizar el correcto funcionamiento del organismo ciudad, la que señala debe presentar un alto grado de higiene y confort como exigencia que la vida moderna impone para hacer agradable y sana la existencia de los habitantes. Junto a la metáfora, expone la ausencia de un plan técnico de expansión por parte de los municipios. Este instrumento lo asume como necesario para que las capitales de provincias y ciudades importantes del país dejen de crecer sin orden ni concierto.

Desde esta idea de ciudad, Carrasco comienza a formular propuestas sobre cómo intervenirla. Si bien hace referencia a la higiene o la vivienda, su preocupación central siempre estará focalizada en un único sentido: metáfora organicista, prioridad a principios estéticos 
10. Sobre esto, amplía y especifica en el artículo "Las Avenidas y Calles. Diversos sistemas de trazados", publicado en diario La Nación, el 31 de diciembre de 1923. (componente moral), trazado de las calles (por sus efectos escenográficos), disposición de monumentos y diseño de jardines y parques públicos. En los distintos trabajos que elaboró, aparece reiteradamente el rechazo junto a una calificación de triste y monótono al trazado de calles en forma de damero. Los mayores elogios están destinados al tipo de trazado que denomina modelo irregular por su particular capacidad de producir efectos felices, aun cuando se lo considere contrario al orden común y presente situaciones hasta cierto punto arbitrarias. ${ }^{10}$

La ubicación de obras ornamentales en la ciudad también será otro punto de gran importancia. La disposición de un monumento en la ciudad (considerando monumentos a obras de artes y obras de arquitectura) debía permitir su observación desde cuatro puntos de vista: en detalle, en conjunto, en relación con el entorno y también en perspectiva, a la que designaba como pintoresca. La importancia no estaba solamente en el valor como obra de arte, sino también en la influencia que ejercía en la educación artística del pueblo. Encontraba una relación directa entre el nivel cultural de la población y el concepto de belleza. Por este motivo afirmaba que cuanto más culto es un pueblo, más se preocupa por su higiene y decorado. Esta visión elitista de la cultura (característica del momento), en la cual se presuponía al artista como un intelectual, colocaba a la persona culta con el fin de educar a la inmensa mayoría de la población inculta.

En cuanto a la higiene y ornato, expone en la ponencia presentada en las Jornadas Agronómicas que en todo plan de urbanización para una ciudad no deben faltar parques y jardines, que deben distribuirse equitativamente en todos los ámbitos de una ciudad formando lo que se llama un sistema de parques (CARrasco, 1923), ya que constituyen los pulmones que purifican el aire. El conjunto de espacios libres, que convenientemente distribuidos forman los clasificados como sitios de desahogo y ambientes purificadores de la atmósfera, es tomado como una cuestión que se desprende directamente de los principios de higiene y salubridad urbana. El diseño de parques fue la actividad en la que más se destacó, motivo por el cual reclama la figura de un especialista (más precisamente de un ingeniero paisajista), que será quien estudie los proyectos y ejecute trabajos de parques y jardines. Entre los elementos que más buscaba para contribuir a lograr el cambio deseado estaba el parque urbano (RAFFA, 2004), entendido como el instrumento privilegiado de la reforma (social, cultural y urbana) y uno de los artefactos urbanos en los que más ambiciones reformistas se depositaron (GoReLIK, 1998). 
El urbanismo como nueva disciplina en Argentina, visto por el especialista Benito J. Carrasco, a través del plan regulador y de extensión para la ciudad de Córdoba, 1927

Sus propuestas son también resultado de una interpretación que hace sobre la ciudad jardín, que tiene más que ver con el concepto de barrio jardín que con el ideario que plantea Howard..$^{11}$ Basándose en su particular interpretación del modelo, elaborará sus primeras propuestas transformándose en el ideal de ciudad para seguir. Carrasco tiene conocimiento de las diferentes experiencias de construcción de ciudades jardín en países europeos, en particular en el Reino Unido. No obstante, sus planteos exponen la desatención a los fundamentos que dieron lugar a ese tipo de ciudades, y se quedan solo con la cuestión estética. El Park Movement norteamericano y la Garden City inglesa ofrecieron un nuevo repertorio de ideas. No obstante, la Garden City fue importada no en su concepción original, sino como modelo de expansión en la idea de suburbio e integración social (Díaz Terreno, 2005). Carrasco propone pensar a la ciudad como jardín en el sentido escenográfico, profundizando poco en las reales consistencias que sostiene el planteo de Howard. Plantea proyectos de embellecimiento que reflejen la imagen de progreso que querían proyectar las elites: el parque relacionado con temas higiénicos, pero, sobre todo, como modelo social y cultural y como modelo de expansión de la ciudad. Como señala Hardoy (1988), la ciudad jardín de Howard nunca fue trasladada a América Latina como tal, la cual habría sido atraída más bien por la idea del suburbio-jardín y el suburbio-jardín-dormitorio para las clases media y trabajadora, respectivamente.

Si bien la postura de Carrasco se puede considerar más cerca del arte urbano que del urbanismo, introduce una cuestión novedosa considerada en el Primer Congreso de la Habitación: la vivienda social y su relación con el plan de ordenación urbanística. Así como pretende en sus propuestas elaborar un discurso específico sobre la ciudad, también se propone ponerlo en valor a partir de una reflexión moral y política. Carrasco entiende que la sociedad de posguerra se encuentra atravesando profundas transformaciones, e identifica dos tendencias. Por una parte, el crecimiento demográfico acelerado en las ciudades y, por otra, la creciente democratización a partir de la adquisición de derechos políticos por parte de la población. La última reclama reformas de las instituciones y será tarea que resolver por parte de los partidos políticos; pero la primera hace referencia a una tarea del urbanismo como disciplina reciente tendiente a mejorar las condiciones de vida en la ciudad. Propone la necesidad de resolver la cuestión habitacional para mejorar la vida de los ciudadanos, siendo solo abordada mediante la definición del lugar físico que debe ocupar la clase trabajadora dentro de la ciudad. Carrasco define barrios obreros en sus proyectos, pero no da cuenta de una preocupación por
11. HOWARD (1850-1928) desarrolla su teoría en Garden cities of tomorrow, edición de 1902 de una versión original aparecida en 1898. 
la vivienda como problemática social, urbana o demográfica. Acentúa, por lo tanto, la segregación de clases al usarlos meramente con fines compositivos y estéticos.

Carrasco intenta definir en sus planteos un modo de abordaje sobre el conocimiento de la ciudad para luego proceder a su transformación, pero se queda en el intento. Reconoce que para iniciar la elaboración de un plan es necesario contar con una serie de estudios previos, que si bien no especifica demasiado, hacen referencia de modo genérico a la topografía, la economía y a cuestiones de distinta índole. Si bien no profundiza ni aclara en qué consisten dichos estudios, no da a conocer aspectos o variables para tener en cuenta, como tampoco una metodología precisa para la elaboración de un plan. Es decir que la síntesis de sus propuestas se puede leer más bien como una recurrencia a los puntos anteriormente resaltados y sobre los cuales siempre mantuvo la atención y la preocupación: el trazado, la ornamentación y los parques.

\section{El plan regulador y de extensión para Córdoba, 1927}

Durante la década de 1920 se evidencian en el centro de la ciudad de Córdoba —el que aún contenía acentuados rastros de la época colonial- las primeras intervenciones específicas, ideas y exploraciones en la búsqueda de modernizar la capital provincial. A principios del siglo XX, la ciudad contaba con una mancha urbana expandida en gran magnitud (2000 hectáreas). Había crecido por fuera de la matriz de las setenta manzanas fundacionales. Este proceso de expansión se inicia a finales del siglo XIX acompañado por un gran aumento demográfico marcado y constante hasta 1914.

Es necesario remarcar también que, tanto Argentina como todo el Cono Sur, tenían más del 50 \% de su población urbanizada desde 1914, mientras que las repúblicas andinas o centroamericanas serían predominantemente rurales hasta los 50 (ВеунAUt, 1985). Durante todo el período colonial, la ciudad de Córdoba experimentó pocos cambios en su fisonomía. Su crecimiento había sido lento y solo se había consolidado la estructura social sobre una estructura urbana que no varió demasiado desde los planos de fundación (Romero, 2001). El cambio se generó entre finales del siglo XIX y 1930, cuando la ciudad experimentó un conjunto de importantes transformaciones. Respuestas oficiales y privadas a esas demandas configuraron la agenda urbana de las dos primeras décadas del siglo XX, especialmente en términos de 
El urbanismo como nueva disciplina en Argentina, visto por el especialista Benito J. Carrasco, a través del plan regulador y de extensión para la ciudad de Córdoba, 1927

reformas higiénicas y habitacionales de los centros históricos, completadas por los suburbios residenciales para una burguesía que se hacía cada vez más cosmopolita (Almandoz, 2002). Algunos de los impactos fueron, por ejemplo, la llegada del tren en 1870, que aceleró la integración de la ciudad a la estructura económica del país y proporcionó la llegada de inmigrantes, conllevando un primer impulso urbanizador a partir de la constitución de barrios por fuera de la cuadrícula colonial inicial (BorxADós, 2000). Los nuevos barrios surgen como expansiones durante el siglo XIX alrededor del centro con la aspiración de cierta autonomía de la ciudad, pero con una fuerte dependencia funcional de su centralidad. Para 1924 se confirma un aumento del $50 \%$ de la población, y las expansiones no pensadas en términos integrales comienzan a ser signos negativos de un desarrollo urbano sin planificación (figura 1). La problemática, por lo tanto, requiere la intervención necesaria de un especialista que disponga las reglas y pautas que seguir en el ordenamiento y crecimiento urbanos.

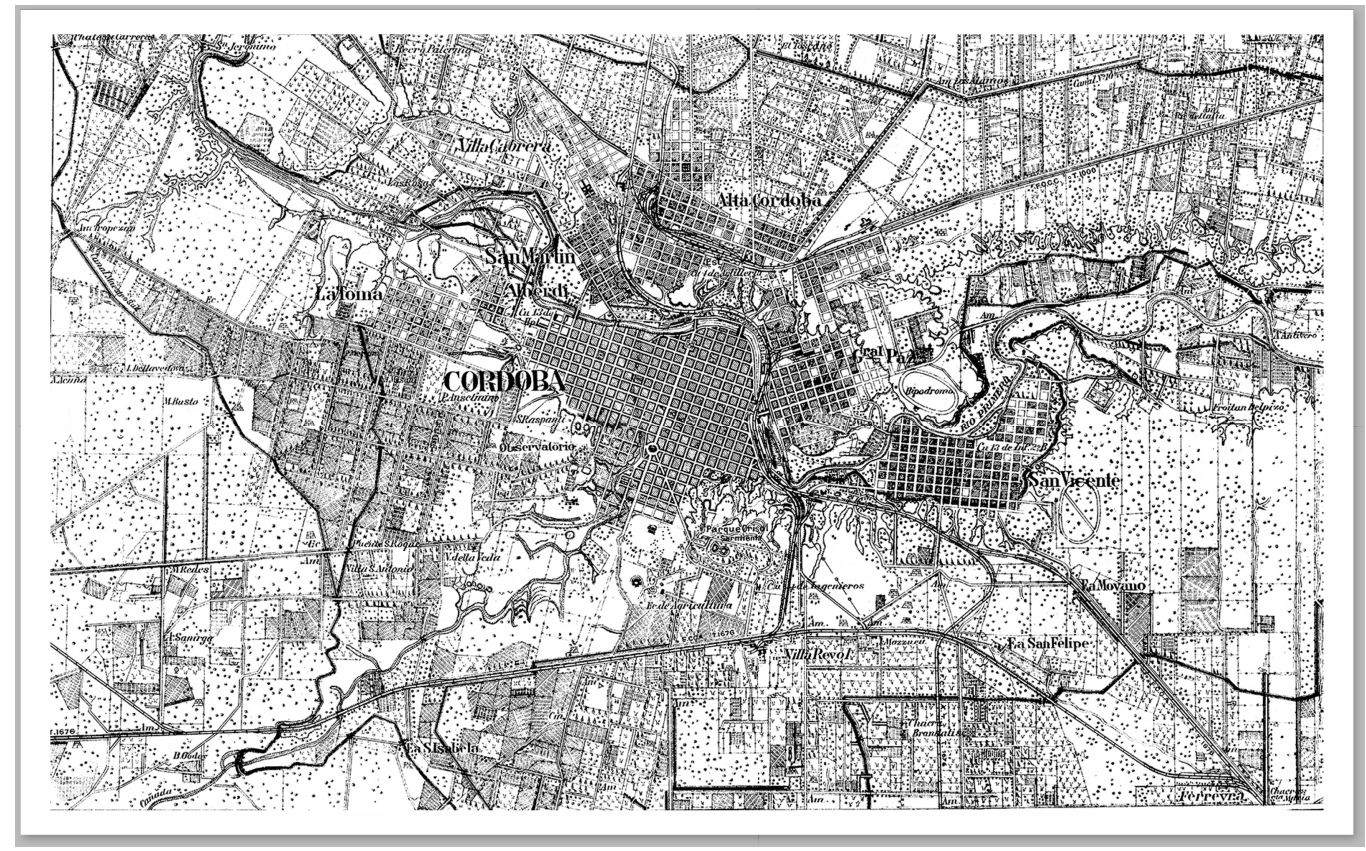

Figura 1.

Planimetría de

la ciudad de

Córdoba, 1924

Fuente: Archivo

Histórico de

la Ciudad de

Córdoba, 1924 
12. Carrasco halaga a las autoridades públicas de Córdoba, quienes tan inteligentemente se compenetraron en la importancia de la disciplina

y dotarán a la ciudad con un "plan regulador y de extensión que tan urgentemente necesita y en cuya virtud ha de ocupar el primer puesto en una evolución tan significativa de la cultura pública" (CARRASCO, 1928a).

13. Señala en la memoria del plan que "era necesario, ante todo, de acuerdo con los principios establecidos, disponer de los planos de planimetría y altimetría del Municipio. Como no existieran, se resolvió levantarlos encargándose del altimétrico la Administración, y del otro la Compañía Aero-fotográfica”.

14. Esta medida será para organizar los alrededores de la ciudad con el consiguiente beneficio para rentas municipales futuras y para el bienestar de los habitantes.

15. Municipalidad de Córdoba, Archivo Histórico Municipal (documentos 1926-4. Secretaría del H.C. Deliberante, comisión de obras públicas-expediente $N .^{o} 2301$, folio 273).

16. Carrasco destaca la locomoción mecánica como factor que complica los problemas en los centros urbanos cambiando hábitos y maneras de vivir, siendo no indispensable habitar en el mismo barrio donde se trabaja,

pudiendo vivir en zonas periféricas donde hay condiciones ventajosas de aire y luz (CARRASCO, 1928a).
En este contexto urbano se involucran y desarrollan gestiones progresistas tanto en la gobernación de la provincia de Córdoba (Ramón J. Cárcano), como en la intendencia de la ciudad (Emilio F. Olmos). Frente a la problemática existente, se plantearon como eje cambiar la fisonomía urbana encarando numerosas obras tanto en el centro como en los barrios ubicados a su alrededor, buscando una modernización urbana y un mejoramiento general para la calidad de vida de la población.

El intendente Olmos (1925-1929), con el convencimiento de transformar la ciudad y pensar el futuro de su desarrollo, decidió encarar un proyecto sistematizado para Córdoba. Se recurrió entonces a la figura de un especialista, y el resultado de ello fue la elaboración del Plan Regulador y de Extensión proyectado por Carrasco en $1927 .{ }^{12}$

Como tarea previa a la elaboración del plan, el especialista Carrasco reclama la confección de un plano actualizado de la ciudad para el estudio de su propuesta de urbanización. ${ }^{13}$ Con el plano de la ciudad, junto al primer relevamiento aero-fotográfico, se estará en condiciones de encarar la propuesta resolutiva de aquellos problemas que Carrasco considera urgentes y futuros. La decisión de ejecutar el proyecto se asienta en la ordenanza de contratación, en cuyo artículo $1 .^{\circ}$ se indican concretamente las tareas que se le encomienda realizar: " $a$. un plan para la ciudad vieja, comprendiendo el proyecto ensanche de la calle 24 de septiembre; $b$. el estudio de las barrancas de Alta Córdoba, Nueva Córdoba y de los barrios Firpo, San Martín, Alberdi, General Paz y San Vicente ${ }^{14}$ c. el plan de distribución de los edificios públicos; $d$. los perfiles de calles, tipo de edificación, parques, arbolados de avenidas y calles, emplazamientos de monumentos y adornos escultóricos, etc.”. ${ }^{15}$

A partir de lo solicitado, Carrasco estructura la Memoria y Expediente Urbano del Plan en tres partes: I. Breves Antecedentes, II. Distintos problemas urbanos de Córdoba y III. Plan adoptado. En la primera parte referencia las distintas instancias en que Córdoba debió ser transformada, introduce la problemática que acarrea la ciudad moderna, sintetiza los conflictos como producto de la locomoción, la falta de higiene y propone como alternativa una vida suburbana. ${ }^{16}$ En la segunda parte, centra la atención en la ciudad de Córdoba, su soporte natural, el trazado hispánico y las expansiones que atravesó a finales del siglo XIX. Por último, trata y desarrolla nuevos tipos de barrios, ferrocarriles, centros cívicos y un 
El urbanismo como nueva disciplina en Argentina, visto por el especialista Benito J. Carrasco, a través del plan regulador y de extensión para la ciudad de Córdoba, 1927

plan de distribución de edificios públicos, vías de circulación y circuitos, sistema de parques y paseos, propuesta para los barrios emergentes de la primera expansión urbana, ámbitos deportivos, mercados, legislación urbana y comisión del plan regulador.

La composición general del plan (figura 2) es descripta como una respuesta al "sistema rectangular combinado con el radial y el pintoresco, es decir, al estilo compuesto o mixto que ha sido preconizado por los urbanistas americanos y franceses como el más conveniente y práctico" (CARRASCO, 1928b). ${ }^{17}$ Se trata de una propuesta que pone el acento en la copia o adaptación acrítica de soluciones elaboradas en otras latitudes a partir de la evidencia de diversas influencias: la ciudad-jardín inglesa, el Park Movement norteamericano, en combinación con los centros cívicos del movimiento City Beautiful y la admiración por las soluciones habitacionales de la Viena Roja (Díaz Terreno, 2005).

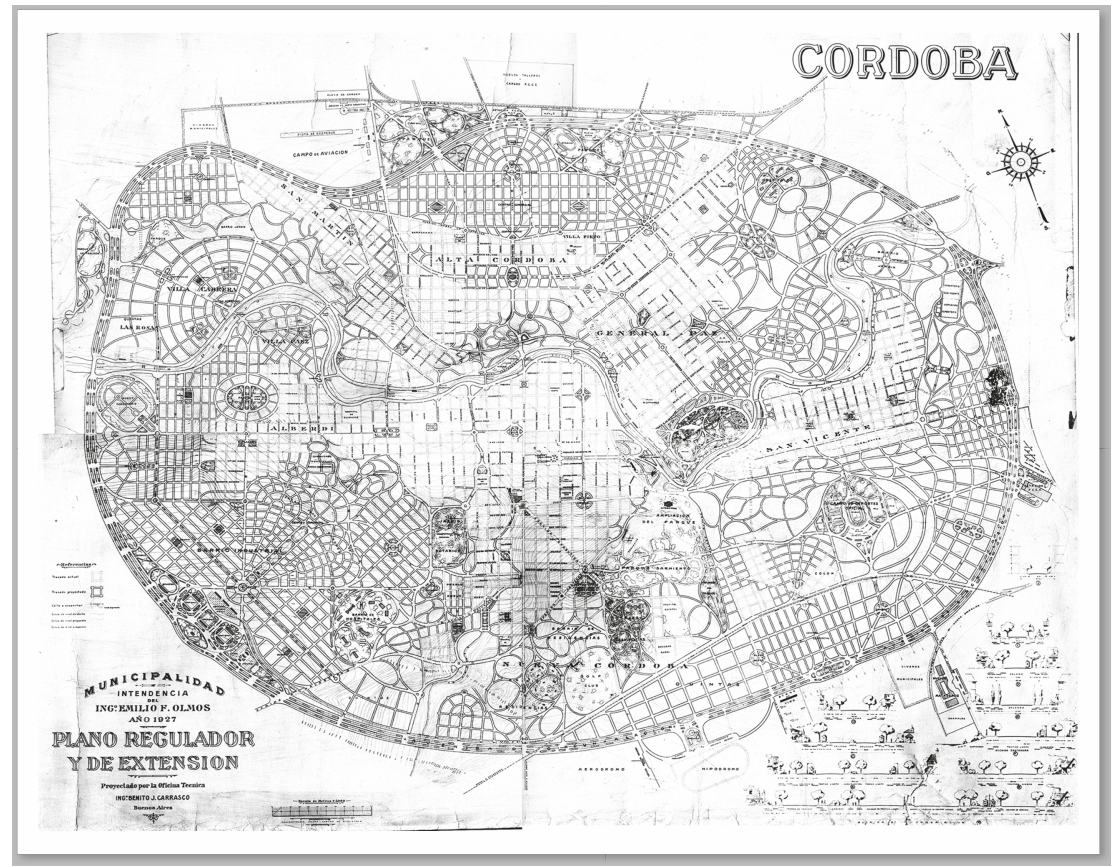

17. Carrasco había desarrollado previamente, en 1923, un modelo ideal denominado Ciudad Nueva, donde todos los dispositivos del trazado de parques eran aplicables $a$ la definición de la forma urbana. Desde el diseño de jardines, y vía trazado urbano, se llegaba al nivel urbano transformando a la ciudad en un gran parque con diagonales $y$ variedad geométrica que diferenciaba distintos sectores con diferentes funciones (industrial, comercial, residencia, viviendas para obreros, etc.).

Figura 2. Planimetría general del Plan Regulador y de Extensión de la Ciudad de Córdoba Fuente: CARRASCO, 1927 
18. Agrupar los edificios públicos, emplazarlos frente a plazas o en focos de perspectivas para jerarquizar su carácter arquitectónico y acompañarlos con intervenciones viales a los fines de hacerlos accesibles.

Figura 3. Croquis del teatro municipal en el cruce de las avenidas Colón y General Paz, de la recova alrededor de la plaza General Paz y de la propuesta para el arroyo La Cañada
Carrasco plantea en su propuesta para Córdoba una ciudad dual: mientras en el centro sistematiza la conectividad y propone centros monumentales, en sus bordes instala nuevos suburbios estructurados por centros de atención (DíAz TERRENO, 2012). El plan propone un modelo de expansión urbana que se sostiene en la descentralización de los equipamientos acompañando a los nuevos barrios suburbanos, al mismo tiempo que en el área central orienta las principales intervenciones a su monumentalización. Localiza los principales centros cívicos en el área central, dominados por los equipamientos más importantes: el palacio municipal frente a la plaza San Martín; el palacio de justicia frente al paseo Sobremonte; la casa de gobierno frente a la plaza España; el palacio legislativo, los museos y exposiciones en la zona del parque Sarmiento; el teatro municipal, rodeado de jardines en Av. Gral. Paz y 24 de Septiembre y el edificio de correos en los terrenos de la Estación del Ferrocarril Central Argentino. Se propone un ambicioso programa de intervenciones monumentales en edificios públicos, parques y bulevares que, si bien responde a sus ideas de beautificación urbana ${ }^{18}$, no está desprovisto de nociones de funcionalidad (figura 3). Plantea centros comerciales y financieros lineales en las áreas pericentrales y centros de atracción en las expansiones suburbanas. Su intención es la de reemplazar la ciudad hispana, la que considera signada por el claustro y el campanario, concibiendo el centro de la ciudad como un área que demanda ser modernizada en su imagen y funcionalidad. Esta búsqueda estará siempre acompañada a partir de una composición desde la higiene, la vialidad y la belleza.

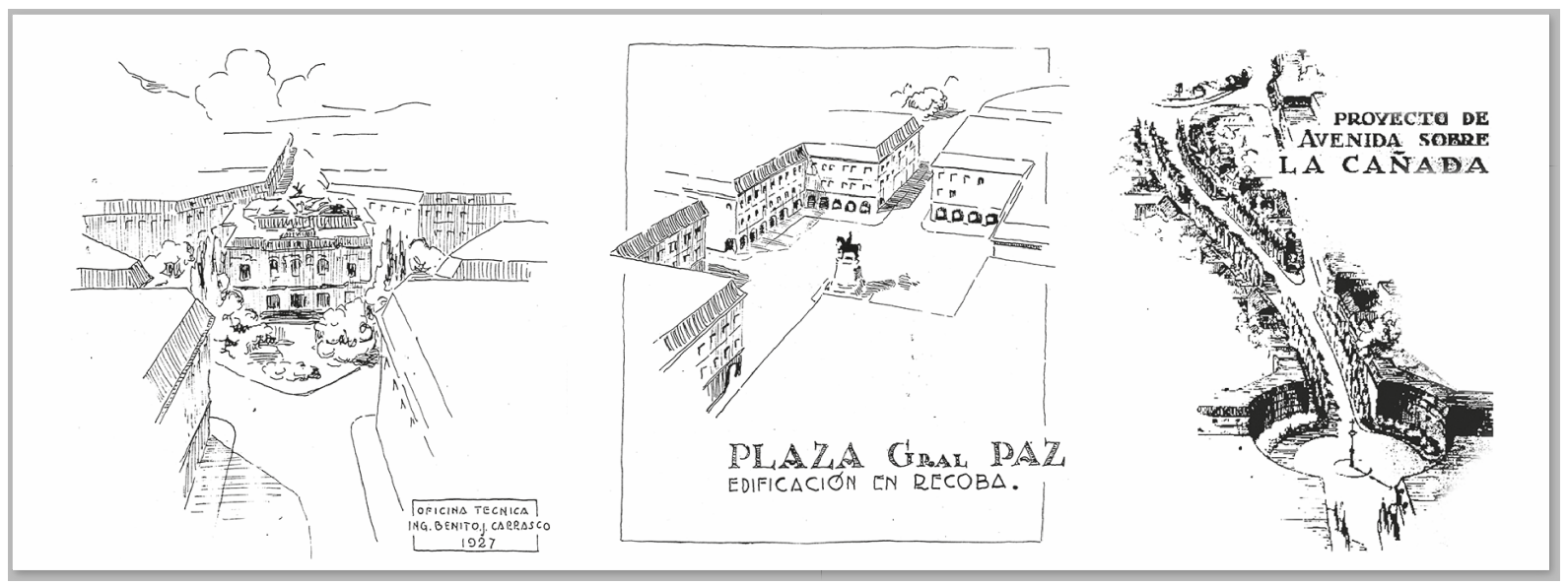


El urbanismo como nueva disciplina en Argentina, visto por el especialista Benito J. Carrasco, a través del plan regulador y de extensión para la ciudad de Córdoba, 1927

En cuanto al planteo sobre el área central, es llamativa la disposición de una gran avenida (figura 4) como propuesta que involucra la vinculación de un nodo central en plaza San Martín y alrededores, con la costanera del río Suquía (otra legítima aspiración de Córdoba, en palabras de Carrasco) junto a la estación de ferrocarril. La propuesta establece además la disposición de un edificio municipal junto a la catedral. En los lineamientos del plan, queda definido que el estilo del nuevo edificio debe concordar con el de la catedral, para constituir así un conjunto armónico que se complementaría con las construcciones que iban a levantarse alrededor de la plaza. Dispone también junto a ello la primera reglamentación especial para el área que establecía la coincidencia de grandes líneas de cornisas y zócalos junto a la fijación de una altura determinada. El nuevo edificio municipal, emplazado en donde existiera el cabildo, debía acompañar en estilo, altura y proporción adecuada para dar protagonismo a la catedral, considerada como la arquitectura más representativa del período colonial en la ciudad.

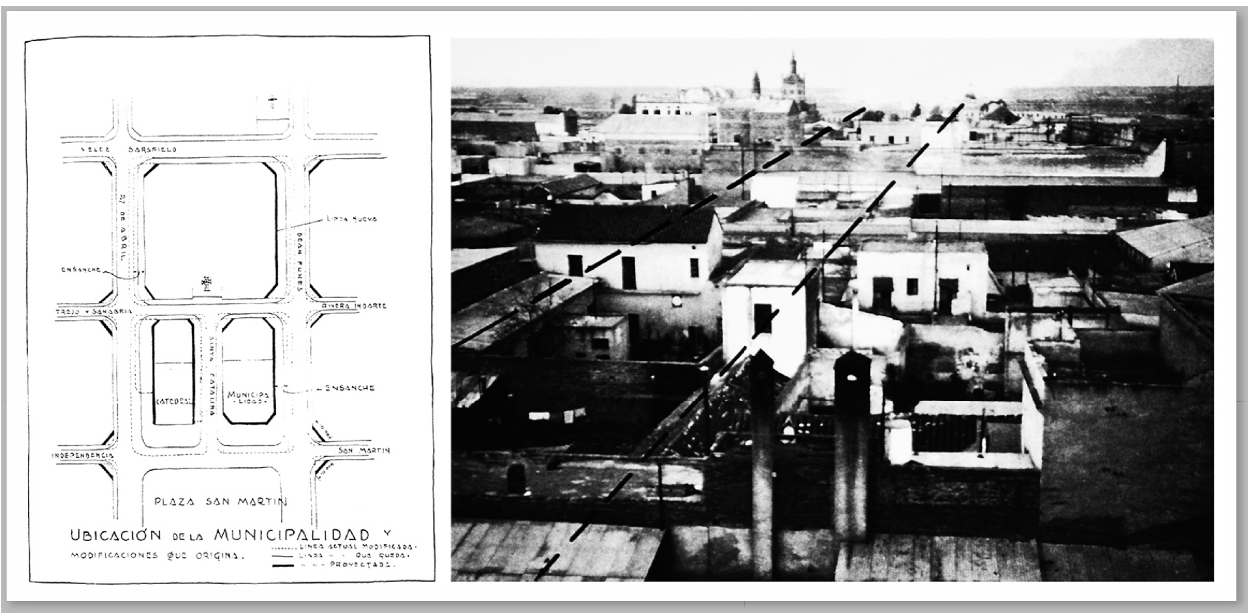

Figura 4. Plano ubicación de la Municipalidad en relación con la catedral y la plaza con las nuevas ochavas y medidas de calles en relación con una foto de la zona afectada por la futura avenida central de penetración Fuente: Plan Carrasco, 1927

En cuanto a espacios públicos, el plan también propone una articulación dual de intervenciones. A escala urbana, la idea de un sistema de grandes espacios verdes. A escala de fragmento o de barrio, el valor está en acompañar los equipamientos con plazas para conformar centros barriales en las nuevas zonas, al mismo tiempo que propone aprovechar los terrenos 


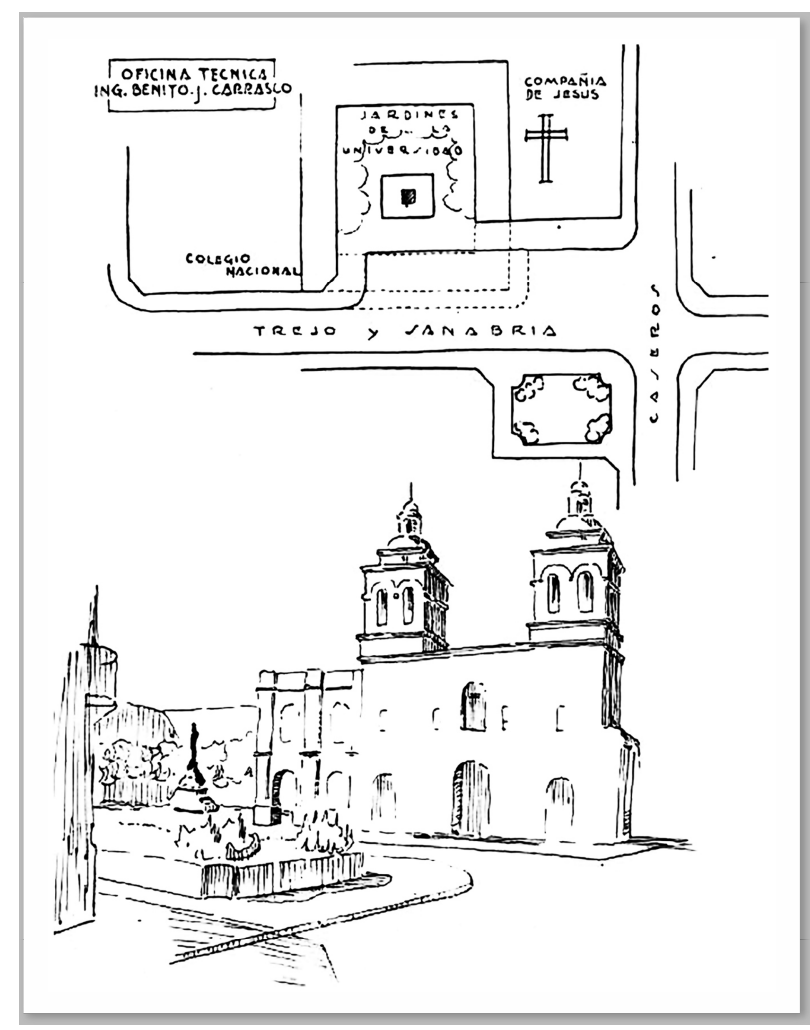

Figura 5. Croquis de la plaza frente a la Iglesia de la Compañía de Jesús, junto a la apertura del patio del rectorado de la universidad. Fuente: Plan Carrasco, 1927 ocupados por edificios públicos para abrir sus jardines al uso colectivo. No obstante, el único detallado en el plan es aquel donde propone la apertura del claustro del rectorado de la universidad junto a una plaza frente a la manzana de la Compañía de Jesús (figura 5).

La cuestión referida a la habitación social, planteada en el Primer Congreso Argentino de la Habitación, es uno de los nuevos temas abordados en el plan que Carrasco elabora para Córdoba. Su propuesta apuesta en parte por la vivienda social para solucionar los temas habitacionales. Esta debe estar, a su entender, vinculada con el interés público y la conquista de los derechos democráticos. Carrasco considera estos nuevos barrios como una obra social que debe resolver los problemas sociales y de higiene, y menciona como ejemplo el programa de mejoramiento social llevado a cabo por la Municipalidad de Viena a partir de 1920 y su forma de financiamiento. Según Carrasco, el problema habitacional debe ser considerado como uno de higiene, pero sobre todo como un problema urbanístico, y por ello promueve su incorporación en el plan. Propone la necesidad de resolver la problemática habitacional para mejorar la calidad de vida de los ciudadanos, pero solo lo aborda mediante la definición del lugar físico que debe ocupar la clase trabajadora dentro de la ciudad. Carrasco define barrios obreros en su propuesta, pero no da cuenta de una preocupación por la vivienda como problemática social, urbana o demográfica, y la utiliza meramente con fines compositivos y estéticos.

En cuanto al sistema viario, propone su diseño en el plan para Córdoba con la intención de que cumpla dos funciones. La primera, como eje paisajístico que una y dé continuidad a los espacios verdes, para convertirse así en un punto esencial del nuevo modelo de ciudad donde los espacios públicos 
El urbanismo como nueva disciplina en Argentina, visto por el especialista Benito J. Carrasco, a través del plan regulador y de extensión para la ciudad de Córdoba, 1927

son el centro. Dentro de este concepto, uno de los aportes más singulares es el eje costanero como una avenida en ambos márgenes del río, atravesada por múltiples puentes con rotondas, como solución para una mejor distribución del tráfico. Para el curso de agua del arroyo la Cañada, propone su entubamiento para construir sobre él una gran avenida. Además del beneficio para el tráfico y la vegetación de la ciudad, lo justifica por la bella perspectiva que se consigue del edificio del Palacio de Justicia.

La segunda función era plantear el sistema viario como instrumento para definir los nuevos trazados de extensión. Introduce como idea la propuesta de recorridos para unir y vincular los diferentes puntos de interés de la trama urbana, y define para ello dos tipos de recorridos: el primero de comunicación rápida y el segundo destinado al disfrute de los paisajes, organizados en tres circuitos anulares. Uno de los circuitos anulares rodea el Centro Histórico, otro une los barrios suburbanos junto a la primera corona de extensión de la ciudad y el último está conformado por un bulevar de circunvalación. De esta forma aparece por primera vez en la ciudad de Córdoba la idea de bulevar (impronta de estilo parisino) como límite de la ciudad y como avenida de circunvalación conectada con todos los caminos de salida. Se estaban gestando, en dichas propuestas, pasos hacia un plan que buscara abarcar la totalidad del espacio de la ciudad como al conjunto de aspectos que determinan su proceso de construcción (DeBAT, 2016), pero aún se carecía de un método específico que lograra llevar a cabo tal tarea, lo que imposibilitaba el ensamble coherente de objetivos con acciones y resultados reales.

Si bien las ideas del plan no se concretaron, la proposición de estos aspectos significó la introducción de ciertos temas urbanos que resultaron recurrentes en distintas propuestas para la ciudad de Córdoba, algunos de los cuales siguen aún hoy vigentes; por ejemplo, considerar que en la actualidad se evidencia que la propuesta de entubar el arroyo de la Cañada no es una realidad concreta, pero sí que la intervención en 1944 sobre dicho espacio de la ciudad ejecutó la idea de paseo en relación con ella como lo planteó inicialmente Carrasco. En cuanto al río Suquía, las calles actuales en la rivera existente no son producto directo de lo propuesto en el plan regulador, pero se podría considerar al plan de Carrasco el primero en plantear esto como idea de partido para dicho espacio de la ciudad. En cuanto al anillo circunvalar, Ernesto La Padula al elaborar el Plan Regulador para Córdoba en 1954 (que se plantea con carácter piloto), parte de la propuesta de Carrasco para ejecutar una circunvalación a la ciudad y proyecta una nueva traza sobre la que se inicia la construcción de la actual avenida de circunvalación y sobre la que aún hoy se encuentra en obra para su 
cierre definitivo. Estos, entre otros posibles, son algunos de los temas propuestos en el plan elaborado por Carrasco, que si bien no generaron el suficiente consenso para su materialización concreta en la ciudad, significaron su introducción en el urbanismo cordobés a lo largo de su devenir.

Siguiendo la dimensión histórica propuesta para la ciudad de Córdoba (MunicipaLIDAD DE CóRDOBA-UNC-FAUD, 2007), se podrían sintetizar las propuestas del plan de Carrasco en las siguientes variables de análisis:

a) Organismo-autor: protagonismo en la figura del especialista, ajeno al ámbito local y en un contexto de escasa tradición planificadora, sin instrumentos apropiados ni oficinas técnicas específicas organizadas para tal fin.

b) Alcance territorial: abarca el ejido municipal definido en 1893 como un cuadrado de 24 $\mathrm{km}$ de lado con un total de $576 \mathrm{~km}^{2}$.

c) Modelo espacial: descongestión de funciones centrales y reconcentración de núcleos barriales. Especialización barrial, que estructura tres tipos de barrios con localización específica: industrial, universitario y nosocomios. Suburbios residenciales en formato barriojardín, con núcleo comunitario y alejado tanto del centro de comercio como del industrial. Problemática habitacional utilizada como elemento compositivo.

d) Crecimiento por expansión: hacia la periferia, con mejores cualidades para la vida urbana. Preocupación por controlar el carácter espontáneo de la extensión, entre otras cosas, a través de un cinturón vial.

e) Sistema vial: nueva red que articula la cuadrícula existente y la traza radial o pintoresca propuesta en los suburbios. Ensanches de calles en la ciudad vieja transformándolas en ejes lineales o bulevares. Planteo de un sistema vial costero y un anillo circunvalar. Relocalización de las estaciones ferroviarias, llevándolas a la periferia por considerarlas un inconveniente para el correcto desenvolvimiento de la ciudad.

f) Área central: ambicioso programa de intervenciones monumentales en edificios públicos, parques y bulevares, que si bien responde a la idea de beautificación urbana, no está desprovisto de nociones de funcionalidad. Centros comerciales y financieros lineales en áreas pericentrales y centros de atracción en las expansiones suburbanas.

g) Soporte natural y ambiente: énfasis en el valor paisajístico del río y las barrancas. Creación de reservas forestales y grandes parques urbanos, considerados pulmones y objeto de interés, desde el punto de vista de la higiene, el ornato y la vialidad. 
El urbanismo como nueva disciplina en Argentina, visto por el especialista Benito J. Carrasco, a través del plan regulador y de extensión para la ciudad de Córdoba, 1927

Como síntesis del plan, se puede establecer que los principios que orientan su elaboración son los propios del pensamiento urbanístico de la época: higiene, belleza y vialidad. La higiene es abordada desde el asoleamiento de los edificios hasta la distribución de actividades junto a espacios libres y sistema de parques en la ciudad. La belleza se asume desde el presupuesto de entender que la homogeneidad morfológica es el patrón que obligadamente habrá de observarse en la construcción de la ciudad. También aparecen las reglas para una correcta distribución de los edificios públicos dentro de la ciudad, la obtención de perspectivas y la protección de las bellezas naturales del sitio. La vialidad se gestiona mediante la conformación de un sistema de arterias de tráfico. De estos tres principios se articulan y desprenden los demás elementos que habrán de formar parte del plan regulador y de extensión.

Se trata entonces de un plan orgánico que refleja la intención de devolver una cierta armonía que se asume como perdida o que nunca se alcanzó. La ciudad vieja se diluye en la nueva a partir de un trazado radial y pintoresquista combinado con el rectangular intentando adecuarse a las curvas de nivel. El sistema de parques, plazas y monumentos actúa como puntos de unión de lo nuevo con lo viejo, todo conectado por anchas y arboladas avenidas que vinculan el centro tradicional con las periferias. Los nuevos barrios se emplazan sobre las barrancas y en los espacios disponibles entre las anteriores expansiones, colocando en el centro de la composición el sector fundacional. Se puede decir entonces que el plan asume a la ciudad como una unidad integral y a sus partes como integrantes de un todo mayor. Se evidencia su postura respecto de que la ciudad debe ser entendida como un organismo vivo, cuyos órganos fundamentales son sus barrios. La ciudad se exhibe así como unitaria a partir de disponer recursos paisajísticos que hacen de ella un gran parque donde habitar.

Respecto de la vivienda, a partir de sus textos introduce explícitamente la necesidad de incorporarla como cuestión inherente al crecimiento y bienestar de la ciudad junto con la posibilidad de encontrar una resolución desde el plan urbano. Los temas se encuentran enunciados en sus escritos, pero no se articulan en propuestas precisas de orden general. En sus diseños priman las estrategias paisajísticas sin incluir significativamente otros aspectos en su pretendida síntesis de lo urbano manifiesta en las premisas. La contradicción entre los textos que refieren a la problemática de la vivienda y a su escaso tratamiento fundido con los recursos compositivos del trazado se puede explicar en parte por la carencia de un dispositivo de abordaje que sistematice las problemáticas y elementos en proposiciones de 
intervención. Sin definir categorías analíticas nuevas ni especificar formas y variables con que se enlazarían los estudios previos mencionados como necesarios, sus planteos quedarán reducidos al trazado, a la composición y disposición de monumentos y edificios y al diseño de parques.

El plan de Carrasco para la ciudad de Córdoba no se concretó más allá del papel y la memoria descriptiva. Se puede asignar la falta de concreción en parte a la inestabilidad política (en 1930 se produce el primer golpe de Estado a un gobierno democrático en Argentina), como también a la inadecuación del plan a la ausencia e inexistencia tanto de una capacidad técnica como de una base financiera del municipio posible de llevar a cabo la envergadura que implicaba la escala y abordaje del plan durante ese momento.

Al año siguiente de elaborar el Plan Regulador para Córdoba, Carrasco fue convocado por la Municipalidad de Concordia en la provincia de Entre Ríos, para desarrollar un Plan Regulador que solucionara los problemas vigentes en dicha ciudad. El diseño del plan para la ciudad de Concordia lo hizo con lineamientos similares a los aplicados en el plan desarrollado para Córdoba. Un año después de firmar el contrato, en agosto de 1929, Carrasco elevó el expediente del plan al presidente municipal (ingeniero Manuel Molaguero), instando a que se lleve a cabo con celeridad. Sin embargo, la propuesta quedó nuevamente trunca y no logró mayores resultados. En el marco de un horizonte de magras realizaciones tanto en términos de elaboración de planes como, mucho más aún, en su puesta en marcha, la gestación de los proyectos de Carrasco para ciudades del interior se convierte en un hecho significativo que se plasma a partir de los recursos usuales del momento, sin aportar una integración efectiva a los nuevos temas y elementos que se enunciaban en sus textos como crítica a los planes anteriores. No obstante, la labor de Carrasco fue importante en cuanto pudo terminar de mostrar y evidenciar los límites y desajustes de la forma en la que se intervenía en la ciudad para ese entonces, y promover no solo algunos temas abordados recurrentemente a lo largo del siglo XX en las propuestas urbanas de Córdoba (la transformación del río en un parque lineal y una vía de circulación rápida, la materialización en calles para los bordes del arroyo La Cañada, la traza de la circunvalación como límite físico y de expansión de la ciudad, la creación de reservas urbanas y parques periféricos, entre otros), sino también la base propositiva como especialista para la emergencia en la construcción del urbanismo como nueva disciplina en Argentina. 
El urbanismo como nueva disciplina en Argentina, visto por el especialista Benito J. Carrasco, a través del plan regulador y de extensión para la ciudad de Córdoba, 1927

\section{Conclusiones}

En 1920, las principales ciudades en Argentina se habían extendido sobrepasando sus límites, fenómeno acentuado previamente por las oleadas de inmigrantes, y se ampliaron gracias a la revolución tecnológica del transporte. Nuevas empresas inmobiliarias junto a nuevas políticas por parte de los municipios motivaban esa expansión hacia la periferia de los denominados sectores populares. El hacinamiento y una cierta inestabilidad social dieron pie para que el urbanismo comenzara a actuar experimentando y dando sus primeros pasos.

Una ciudad bella, trazados interesantes, sistemas de parques, perspectivas y puntos de vista, distribución de centros cívicos siguiendo principios estéticos, grandes parques urbanos serán las metas que Carrasco se propone alcanzar para la transformación de la ciudad moderna. Todas ellas aparecen en el plan para Córdoba como elementos urbanos. Concepciones del arte urbano clásico en las cuales subyace la idea de que la ciudad es un todo posible de organizar según grandes perspectivas y ejes de simetrías. Concepciones que atraviesan en todos los sentidos sus ideas acerca del urbanismo y del plan.

Como primera impresión sobre Carrasco, surge que existe una contradicción entre el discurso y la práctica, en particular en sus referencias a la vivienda social. No logra avanzar más allá de la expresión de un deseo: que todos los trabajadores tengan una vivienda, que sean los empresarios quienes resuelvan el problema; y si lo hacen, por supuesto, que sea de manera estética y compositiva. Queda claro que con el plan se propone lograr una ciudad más bella, pero además también se pueden otorgar otras intenciones que permiten suponer que se está frente a principios propios del reformismo social; "se aprecia en las palabras de Carrasco cómo el concepto de planificación urbana no está unido solamente a la idea de orden, sino, principalmente, a la concepción de reforma social” (Gómez Pintus, 2008). El plan es asignado con el rol de resolver problemas de índole social, presuponiendo que una modificación en el ámbito físico promueve transformaciones en las conductas sociales. Sin embargo, la cuestión de la vivienda solo encuentra resolución como un elemento más de la composición estética de la ciudad y no como solución a una necesidad social.

El plan que propone para Córdoba concentra las ideas urbanas dominantes de la década: ideas higienistas, funcionalistas y estéticas. La ciudad es abordada como un todo, compuestos 
por partes, que debe funcionar como una unidad a partir de recursos viales, paisajísticos y estéticos. No obstante — como se mencionó-, cabe aclarar que las propuestas no generaron el suficiente consenso para su materialización, ya que fue una buena intención con poca transcripción a la realidad. Se puede asignar la falta de concreción en parte a la inestabilidad política, como también a la inadecuación del plan a la ausencia de capacidad técnica y financiera del municipio durante ese momento. Es importante destacar que Carrasco introdujo, a través del plan, temas que resultaron recurrentes dentro del urbanismo cordobés a lo largo del siglo XX. La propuesta conceptual y de diseño respecto de lo urbano y lo paisajístico significan, por lo tanto, un modelo alternativo $-\mathrm{y}$ hasta utópico- de la realidad urbana de entonces.

En cuanto a la constante preocupación por el verde (promovida y tematizada por paisajistas que procuraban dar a su especialidad una nueva relevancia social y nuevas esferas de acción), se escondían perspectivas diversas. El diseño de jardines como matriz del arte urbano, el verde como pulmón o vector de la moralización de las clases trabajadoras, la regulación del asoleamiento desde el trazado viario, las reservas de tierras y los sistemas de parques como matriz de aglomeraciones metropolitanas, entre otras. Todas remitían a la disposición de extensiones libres de construcción junto a una fuerte presencia de vegetación; pero los argumentos justificadores, las normas y sus pretendidos alcances eran divergentes.

La década del 20, desde el plan de Carrasco, se entiende como un momento en que el llamado especialista produce planes urbanos, el trazado es el elemento prácticamente excluyente a partir del cual se define el plan y en el cual la problemática emergente de la vivienda solo es abordada parcialmente y como elemento compositivo y estético. Este núcleo explicativo pone de relieve una estrategia de legitimación de un conjunto de prácticas de intervención urbana en un paradigma científico, en ese momento en pugna por su institucionalización (Rigotri, 2003). El plan para Córdoba es un claro exponente de las ideas del urbanismo del momento y de los primeros intentos de zonificación con el criterio de a cada cual su lugar en la ciudad. Se podría concluir, por lo tanto, que este momento, como afirma Bragos (1998), significó el inicio de una transición entre la ciudad bella y la ciudad útil, entre el arte urbano y el urbanismo. 
El urbanismo como nueva disciplina en Argentina,

visto por el especialista Benito J. Carrasco, a través del plan regulador y de extensión para la ciudad de Córdoba, 1927

\section{Bibliografía}

ALMANDOZ, Arturo (2013) Modernización urbana en América Latina. De las grandes aldeas a las metrópolis masificadas. Colección Estudios Urbanos-UC, Santiago de Chile.

(2007). "Modernización urbanística en América Latina. Luminarias

extranjeras y cambios disciplinares, 1900-19601”. En, Iberoamericana, N. ${ }^{\circ} 27$.

(2002). "Urbanization and Urbanism in Latin America: From Hauss-

mann to CIAM”. En: Planning Latin America's Capital Cities, 1850-1950. Routledge, Londres-Nueva York.

BEYHAUT, Gustavo (1985) Historia universal Siglo XX. América Latina. III. De la independencia a la segunda guerra mundial. Siglo Veintiuno Editores, México D. F.

BOIXADós, María Cristina (2000) Las tramas de una ciudad, Córdoba entre 1870 y 1895. Élite urbanizadora, infraestructura, poblamiento. Ferreyra Editor, Córdoba.

BRAGOS, Oscar (1998). "La primera generación de planes reguladores en la Argentina. Del arte urbano al urbanismo”. Ponencia presentada en el V Seminário de História da Cidade e do Urbanismo. Cidades: temporalidades em confronto. Organizado por la Pontifícia Universidade Católica de Campinas, Faculdade de Arquitetura e Urbanismo en junio de 1998 en la ciudad de Campinas, Brasil.

(1997) Urbanismo y urbanistas en la primera mitad del siglo XX. Propuestas para la transformación de la ciudad y de la sociedad. Escuela Técnica Superior de Arquitectura de la Universidad de Valladolid, Rosario-Valladolid.

(1991). "Los primeros planes para las grandes ciudades latinoamericanas". En: Cuadernos del CURDIUR, N. ${ }^{\circ} 55$.

BRARDA, Analía (2012). "Rosario imaginada, ciudad planificada: el plan regulador y de extensión del año 1935”. En: Experiencias de urbanismo y planificación en la Argentina 19001955. CEDODAL, Buenos Aires.

CANAVESSI, Carlos Rogelio (2012). "Plan Carrasco para Concordia (Entre Ríos), 19281929”. En: Experiencias de urbanismo y planificación en la Argentina 1900-1955. CEDODAL, Buenos Aires.

CARRASCO, Benito Javier (1923) Parques y Jardines. Talleres Peuser, Buenos Aires. (1927). “Córdoba, Plan Regulador y de Extensión. Memoria y Expediente urbano”. Biblioteca FAUD-UNC, Córdoba.

(1928a). "Plan para la urbanización de Córdoba”. Diario La Na-

ción, 29 de enero. 
(1928b). "Plan de Urbanización de Córdoba”. Diario La Prensa, Tercera Sección, 5 de febrero.

COLLADO, Adriana (2007) Modernización urbana en ciudades provincianas de Argentina. Teoría, modelos y prácticas, 1887-1944. Tesis doctoral. Programa de doctorado en Historia del Arte y la Arquitectura Iberoamericana, Universidad Pablo Olavide de Sevilla, España. DEBAT, Mariana (2016) Entre la abstracción y la realidad. Ideas y estrategias de ciudad en la construcción de Córdoba y Rosario. Tesis doctoral. Programa de doctorado en Urbanismo, Departamento de Urbanismo y Ordenación del Territorio, Universidad Politécnica de Cataluña, España. DELLA PAOLERA, Carlos María (1926). "La evolución de las ciudades”. Diario La Razón, 4 de marzo.

DÍAZ TERRENO, Fernando (2012). "Parque, suburbio y centro cívico en Córdoba. El plan Regulador y de Extensión, 1927 Benito J. Carrasco”. En: Experiencias de urbanismo y planificación en la Argentina 1900-1955. CEDODAL, Buenos Aires.

(2005). "Los territorios periurbanos de Córdoba. Entre lo genérico y lo específico”. En: Revista Iberoamericana de Urbanismo, N . 5.

GALIMBERTI, C. I. (2016). "Planificar el territorio metropolitano: historia de la planificación regional de Rosario (1935-1976)”. En: Revista de Historia Americana y Argentina, Vol. $51,{ }^{\circ}{ }^{\circ} 1$.

GÓMEZ PINTUS, Ana (2000). "Entre la ciudad del ocio y la ciudad del trabajo. La recepción de la ciudad jardín en Argentina”. En: Arquitextos, N. ${ }^{\circ} 096.07$.

GORELIK, Adrián (1998) La grilla y el parque. Espacio público y cultura urbana en Buenos Aires, 1887-1936. Editorial Universidad Nacional de Quilmes, Buenos Aires.

GUTIÉRREZ, Ramón (2007). "Los inicios del urbanismo en la Argentina. Parte 1. El aporte francés”. En: Arquitextos, N. ${ }^{\circ} 087.01$.

(1995). "Modelos e imaginarios europeos en urbanismo americano 1900-1950”. En: Revista de Arquitectura, N. ${ }^{\circ} 8$.

HARDOY, Jorge E. (1988). "Teorías y prácticas urbanísticas en Europa entre 1850 y 1930. Su traslado a América Latina”. En: Repensando la ciudad de América Latina. Grupo Editor Latinoamericano, Buenos Aires. (1926). "Consideraciones sobre la urbanización de la ciudad de Buenos Aires”. Diario La Razón, 30 de julio.

MARTÍNEZ, Josefa y RETTAROLI, José María (1994) Evolución histórica de la planta urbana de la ciudad de Córdoba. Tomo II. Período: primera expansión. 1880-1930. FAUDUNC, Córdoba. 
El urbanismo como nueva disciplina en Argentina,

visto por el especialista Benito J. Carrasco, a través del plan regulador y de extensión para la ciudad de Córdoba, 1927

MARTÍNEZ DE SAN VICENTE, Isabel (1986). “Rosario: Plan regulador 1929-1935”. En: Documentos de Arquitectura Nacional Americana, N. 22.

MOLINA Y VEDIA, Juan (1999) Mi Buenos Aires herido. Planes de desarrollo territorial y urbano (1535-2000). Ediciones Colihue, Buenos Aires.

MUNICIPALIDAD DE CÓRDOBA-UNC-FAUD (2007). "Bases para el Plan director de la ciudad de Córdoba. Informe Preliminar 1”. FAUD, UNC, Córdoba.

NOVICK, Alicia (2009). "Las dimensiones de la ciudad desde los planes y proyectos". En: Revista Registros, N. ${ }^{\circ} 6$.

(2000). "Planes versus proyectos: Algunos problemas constitutivos del Urbanismo Moderno. Buenos Aires (1910-1936)”. En: Revista de Urbanismo, N. ${ }^{\circ}$.

(1993). "El Museo Social Argentino. La ciudad desde el campo”. En: Serie Crítica IAA-FADU/UBA N. ${ }^{\circ} 46$.

NOVICK, Alicia y PICCIONI, Raúl (2004). “Urbanismo”. En: Diccionario de Arquitectura. Tomo SJZ. Editorial Clarín, Buenos Aires.

(1990). “Carlos María Della Paolera (1890-1960). Los orígenes de la profesión de urbanista en la Argentina”. En: Serie Crítica. IAA-FADU/UBA, N. 16. OUTTES, Joel (2002). "Disciplinando la sociedad a través de la ciudad: El origen del urbanismo en Argentina y Brasil (1894-1945)”. En: Revista EURE, Vol. 28, N. 83.

PAGE, Carlos (1991) Propuestas e intervenciones urbanas en Córdoba 1880-1930. FAUD-UNC, Córdoba.

RAFFA, Cecilia (2004). "El urbanismo de Benito Carrasco: entre Parques y Jardines y la propuesta para la ciudad de Mendoza”. En: Registros N. ${ }^{\circ} 2$.

RIGOTTI, Ana María (2009). "De la ciudad al territorio, del municipio a la nación: las promesas del urbanismo como alternativa tecnocrática de gestión (1928/1958)”. En: Los saberes del Estado. Edhasa, Buenos Aires.

(2005) Las invenciones del Urbanismo en Argentina (1900-1960). Inestabilidad de sus representaciones científicas y dificultades para su profesionalización. Mimeo, Rosario.

(1997). "Il piano regolatore di Rosario. Fra la riforma civica e l'autono-

mia professionale (1925/1951)”. En: Storia Urbana $N .^{\circ} 78$.

ROMERO, José Luis (2001) Latinoamérica, las ciudades y las ideas. Siglo Veintiuno Editores, Buenos Aires.

SICA, Paolo (1978) Storia dell Urbanistica. II Novecente. Laterza, Roma.

SUÁREZ, Odilia (1994) Planes y códigos para Buenos Aires, 1925-1985. FADU-UBA, Buenos Aires. 